\title{
Apnea of prematurity: from cause to treatment
}

\author{
Jing Zhao $\cdot$ Fernando Gonzalez $\cdot$ Dezhi Mu
}

Received: 27 November 2010 / Accepted: 24 January 2011 /Published online: 8 February 2011

(C) The Author(s) 2011. This article is published with open access at Springerlink.com

\begin{abstract}
Apnea of prematurity (AOP) is a common problem affecting premature infants, likely secondary to a "physiologic" immaturity of respiratory control that may be exacerbated by neonatal disease. These include altered ventilatory responses to hypoxia, hypercapnia, and altered sleep states, while the roles of gastroesophageal reflux and anemia remain controversial. Standard clinical management of the obstructive subtype of AOP includes prone positioning and continuous positive or nasal intermittent positive pressure ventilation to prevent pharyngeal collapse and alveolar atelectasis, while methylxanthine therapy is a mainstay of treatment of central apnea by stimulating the central nervous system and respiratory muscle function. Other therapies, including kangaroo care, red blood cell transfusions, and $\mathrm{CO}_{2}$ inhalation, require further study. The physiology and pathophysiology behind AOP are discussed, including the laryngeal chemoreflex and sensitivity to inhibitory neurotransmitters, as are the mechanisms by which different therapies may work and the potential longterm neurodevelopmental consequences of $\mathrm{AOP}$ and its treatment.
\end{abstract}

Keywords Apnea of prematurity. Premature infant . Neurodevelopment $\cdot$ Methylxanthine therapy Continuous positive airway pressure

J. Zhao $\cdot \mathrm{D} . \mathrm{Mu}(\square)$

Department of Pediatrics, West China Second University Hospital, Sichuan University,

Chengdu, China

e-mail: dezhi.mu@ucsf.edu

F. Gonzalez $\cdot$ D. Mu

Departments of Neurology and Pediatrics,

Newborn Brain Research Institute, University of California,

San Francisco, CA, USA

\section{Introduction}

During the first few days of life, premature infants encounter problems with temperature regulation, acquisition of oral feeding skills, and the normal control of respiration [85]. Resolution of apnea and establishment of a normal respiratory pattern is a major developmental milestone for many premature infants. The most widely used definition of apnea of prematurity (AOP) specifies a pause of breathing for more than 15-20 s, or accompanied by oxygen desaturation $\left(\mathrm{SpO}_{2} \leq 80 \%\right.$ for $\left.\geq 4 \mathrm{~s}\right)$ and bradycardia (heart rate $<2 / 3$ of baseline for $\geq 4 \mathrm{~s}$ ), in infants born less than 37 weeks of gestation [55].

While AOP is a developmental disorder, the reasons behind the propensity for apnea in immature infants are not entirely clear. Although the pathogenesis of AOP is poorly understood, the immature pulmonary reflexes and breathing responses to hypoxia and hypercapnia likely contribute to the occurrence or severity of AOP [24, 70]. It may also be exacerbated by a number of coexisting factors or disease states $[6,52]$.

Severe apnea that lasts longer than $20 \mathrm{~s}$ is usually associated with bradycardia or desaturation, which may lead to disturbances of cerebral hemodynamics and possibly affect neurodevelopmental outcome. However, it is difficult to prove a link between apnea and poor neurodevelopmental outcomes due to a number of comorbidities and confounding factors affecting neurological development in premature infants. Therefore, evaluating the consequences of AOP on long-term neurodevelopment remains a challenge.

AOP treatment options are fairly limited and include prone positioning, methylxanthine therapy, and nasal intermittent positive pressure ventilation (NIPPV) or continuous positive airway pressure (CPAP) $[34,54,63,71]$. 
Other reported treatments such as sensory stimulation, $\mathrm{CO}_{2}$ inhalation, and red blood cell transfusions are not widely used and require further examination $[3,8,13]$. Since the pathogenesis and long-term neurodevelopmental effects of AOP are poorly understood, and the optimal treatment for AOP is not clear, this review discusses recent findings regarding pathogenesis, mechanisms underlying treatment, and consequences of AOP in premature infants.

\section{Incidence}

The incidence of AOP is inversely correlated with gestational age and birth weight. Seven percent of neonates born at 34 to 35 weeks gestation, $15 \%$ at 32 to 33 weeks, $54 \%$ at 30 to 31 weeks [50], and nearly all infants born at $<29$ weeks gestation or $<1,000 \mathrm{~g}$ exhibit AOP [73]. It is generally broken down into three subtypes: central, obstructive, or mixed [85]. Central apnea accounts for approximately $10 \%$ to $25 \%$ of all cases of apnea, with obstructive apnea accounting for $10 \%$ to $25 \%$ and mixed for $50 \%$ to $75 \%$. In each individual infant, one of these subtypes tends to predominate [85].

The incidence of bradycardia is fairly similar across these different groups; however, bradycardia does appear to occur more frequently with longer duration of apnea. Bradycardia occurs in $10 \%$ of apneic events with duration of $10-14 \mathrm{~s}, 34 \%$ of apnea lasting $15-20 \mathrm{~s}$, and $75 \%$ of apnea that lasts $>20 \mathrm{~s}$. Bradycardia usually occurs following oxygen desaturation that is associated with apnea, with a recent study demonstrating an earlier onset of oxygen desaturation than bradycardia (median interval $4.2 \mathrm{~s}$ ) [68]. However, recovery from bradycardia often precedes the recovery in oxygen saturation after apnea [68]. Bradycardia may also follow apnea without desaturation, possibly mediated by vagal nerve stimulation and not necessarily by hypoxemia.

\section{Pathogenesis}

AOP is a developmental disorder that self-resolves. In most cases, AOP likely reflects a "physiological" rather than a "pathological" immature state of respiratory control.

Fetal to neonatal transition

The fetus moves from an oxygen-poor environment, with $\mathrm{PaO}_{2}$ of $23-27 \mathrm{mmHg}$, to an oxygen-rich environment after birth that provides a fourfold increase in $\mathrm{PaO}_{2}$ [51]. The postnatal rise in $\mathrm{PaO}_{2}$ effectively silences peripheral chemoreceptors, resulting in delayed onset of spontaneous breathing, especially when neonates are exposed to $100 \%$ oxygen during postnatal resuscitation [94]. Therefore, neonates need to quickly adjust their ventilation to adapt to the postnatal environment. The immature respiratory pattern and chemoreceptor function in premature infants may delay this postnatal adjustment, given fewer synaptic connections and poor myelination of the immature brainstem [25].

Ventilatory response to hypoxia

The ventilatory response to hypoxia after birth in premature infants elicits an initial transient increase in respiratory rate and tidal volume that lasts for 1-2 min, followed by a late, sustained decline in spontaneous breathing that may last for several weeks $[31,59]$. This late decline in spontaneous breathing is termed hypoxic ventilatory depression, which may be associated with the delayed postnatal respiratory adjustment that occurs in premature infants.

Peripheral chemoreceptor stimulation may also lead to apnea secondary to hypocapnia seen after hyperventilation [17]. The $\mathrm{CO}_{2}$ level can decrease to a level near the apneic threshold (1-1.3 mmHg below baseline $\mathrm{CO}_{2}$ level) [42]. The relative proximity of the apneic threshold of $\mathrm{CO}_{2}$, together with peripheral chemoreceptor activation in response to hyperventilation, may lead to apnea.

\section{Ventilatory response to hypercapnia}

In response to hypercapnia, premature infants increase ventilation by prolonging the period of expiration, but not increasing breath frequency or overall tidal volume, leading to less minute ventilation than that seen in term infants. This poor hypercapnic ventilatory response is more pronounced in premature infants with apnea than without apnea [24]. Contradictory movements of respiratory muscles in response to hypercapnia may also play a role in AOP. In a study of piglets exposed to hypercapnia, researchers found that resultant diaphragm activation prior to upper airway muscles activity results in obstructed inspiratory efforts and prolonged apneic events [18].

Ventilatory responses to laryngeal chemoreflex

Activation of the laryngeal mucosa in premature infants can lead to apnea, bradycardia, and hypotension [70]. While this response is assumed to be a protective reflex, an exaggerated response may cause AOP. This reflex-induced apnea is termed the laryngeal chemoreflex and is mediated through superior laryngeal nerve afferents [41, 83, 87].

Neurotransmitters and apnea

Enhanced sensitivity to inhibitory neurotransmitters, such as gamma-aminobutyric acid (GABA), adenosine, seroto- 
nin, and prostaglandin, is another feature of the premature infant's respiratory control system [50]. GABA is the major inhibitory neurotransmitter in the CNS. In piglets, GABAergic neurons were activated during hypercapnia [99]. Blocking of $\mathrm{GABA}_{\mathrm{A}}$ receptors prevented ventilatory depression and increased respiratory rate in response to hypercapnia [78].

Adenosine is a product of adenosine triphosphate and is formed as a consequence of metabolic and neural activity in the brain, especially during hypoxia. Recent reports have found an interaction between adenosine and GABA in the regulation of breathing [1,98]. This association is further strengthened by the observations that adenosine receptors are expressed in GABA-containing neurons. The binding of adenosine to its receptor may be involved with the release of GABA and thus inhibit respiration leading to apnea [98].

Genetic variability and apnea

Recently, researchers found that the heritability of AOP was $87 \%$ among same-gender twins [12]. These findings raise the possibility that AOP has an important genetic basis. Tamim et al. [86] first reported a higher proportion of firstdegree mating for infants with AOP compared with those without AOP. Genomic studies may provide further information on the pathogenesis that underlies AOP.

\section{Effects of sleep state and movements on apnea}

Breathing and behavioral states are closely interrelated [44]. Premature infants spend a large proportion of their time in rapid eye movement (REM) sleep, with a relatively smaller amount in wakefulness. During REM sleep, these infants have more paradoxical breathing with a less stable baseline of oxygen saturation [69]. Therefore, apnea occurs more frequently in REM sleep than in quiet sleep [44, 74]. Arousal from REM sleep appears to be a precursor to apnea associated with oxygen desaturation in premature infants since motor activities after arousal are typically associated with laryngeal closure [44]. Therefore, movements frequently precede or occur simultaneously with apnea, and arousal from sleep may cause the apnea rather than terminate it.

\section{Factors involved in apnea}

While immature respiratory control is the primary cause of apnea in the premature infant, many coexisting factors can potentiate or worsen apnea. Apnea is a common presenting sign of both local and systemic infection [39, 84]. Apnea can be triggered by a number of central nervous system diseases, including intracranial hemorrhage, hypoxicischemic encephalopathy, and seizures. Thermoregulation may also play a role in apnea. Exposure to cooler temperatures decreased the duration and frequency of AOP, while elevated body temperature increased the incidence of AOP, suggesting that apnea is related to metabolic state and environmental temperature [91].

Other factors that have been associated with apnea in premature infants include glucose or electrolyte imbalance [85], as well as the presence of a patent ductus arteriosus with a large shunt [58]. A number of medications, including narcotic analgesics and magnesium sulfate, can lead to apnea in infants [85]. Anemia is also associated with apnea because of lowered oxygen-carrying capacity of red blood cells that leads to hypoxia, resulting in respiratory depression [11].

Gastroesophageal reflux and AOP are both occurring commonly in premature infants. However, the relationship between them remains controversial. Slocum et al. [89] set up a reflux model with rapid infusions of graded volumes of air into the esophagus of newborns to study this association. They did not find an association with apnea. Esophageal $\mathrm{pH}$ monitoring is the conventional method to test for the presence of acid reflux from the stomach [27]. Since infants receive frequent milk-based feedings, which continually buffer stomach acid, measured $\mathrm{pH}$ may be neutral or even alkaline in some cases [20]. Therefore, esophageal $\mathrm{pH}$ may significantly underestimate the frequency of reflux episodes in premature infants and may not identify AOP events resulting from nonacid reflux [20]. Multichannel intraluminal impedance technology has been used recently to monitor electrical impedance in the esophagus, which may provide a more comprehensive measure of reflux. In conjunction with $\mathrm{pH}$ measurement, multichannel intraluminal impedance can increase the sensitivity of reflux detection and the identification of both acid and nonacid reflux [21]. Even with these improved detection methods, researchers have not found an association between gastroesophageal reflux and apnea $[56,65]$. Therefore, the majority of apneic episodes do not appear to be related to gastroesophageal reflux, though in a specific subset of events, a causal relationship may exist [80]. As a result, there is no evidence to support the use of anti-reflux medications for the treatment of AOP [89]. On the other hand, apnea may periodically lead to increased reflux. Recently, researchers found that the lower esophageal sphincter pressure was decreased during apneic episodes [61].

Other factors-including neck flexion, nasal obstruction, and delayed gastric emptying - have also been linked to apnea. Neck flexion interferes with neuromuscular regulation of pharyngeal patency and can produce intermittent airway obstruction [95]. Nasal edema or the presence of a nasogastric feeding tube also increases nasal airway resistance. Delayed gastric emptying can also increase 
apneic events since abdominal distension reduces lung volume and increase vagal afferent feedback [88].

\section{Interventions for premature infants with apnea}

Interventions for AOP include efforts to reduce work of breathing and/or increase respiratory drive. The latest in AOP treatment will be discussed below.

Effective interventions

\section{Prone position}

Prone positioning can improve thoracoabdominal synchrony and stabilize the chest wall without affecting breathing pattern or $\mathrm{SpO}_{2}$ [60]. Several studies have demonstrated that prone position reduces AOP [10,69]. Extension of the neck $15^{\circ}$ from the prone position is referred to as the head elevated tilt position, which has been found to decrease episodes of oxygen desaturation by $48.5 \%$ [77]. A more comfortable three-stair-position that maintains the head and abdomen in a horizontal position was reported to improve apnea, bradycardia, and desaturation [7]. However, head elevated tilt position has not been shown to work in combination with pharmacologic therapy. Recently, two randomized controlled trials investigated the effect of three different postural interventions on the incidence of bradycardia and desaturation. The researchers found that the effect of head elevated tilt position and three-stair-position interventions following aminophylline treatment was similar to standard prone positioning and only decreased the rate of desaturation by $12 \%[7,71]$. Thus, in infants receiving other effective treatment, neither head elevated tilt position nor three-stair-position resulted in a further improvement in AOP. Since head elevated tilt position and three-stair-position are easy to provide, it should be considered as a first-line intervention in infants with AOP.

\section{Continuous positive airway pressure and nasal intermittent positive pressure ventilation}

CPAP at 4-6 $\mathrm{cmH}_{2} \mathrm{O}$ has proven a safe and effective therapy for AOP over the past 35 years. CPAP delivers a continuous distending pressure via the infant's pharynx to the airways to prevent both pharyngeal collapse and alveolar atelectasis. Therefore, CPAP can enhance functional residual capacity and reduce the work of breathing, improving oxygenation and decreasing bradycardia [26, 63]. CPAP works effectively to reduce the incidence of obstruction, but it has no clear efficacy in central AOP [53].

An extension of CPAP is the administration of NIPPV. Systematic meta-analysis has shown it to be effective in preventing extubation failure and for the treatment of AOP [45]. A randomized crossover trial [63] found that variableflow nasal continuous positive airway pressure (NCPAP) is more effective in treating AOP than a conventional ventilator using NIPPV mode. In a word, reduced work of breathing may be the key to improving AOP, which can be achieved via either synchronized NIPPV [54] or variableflow NCPAP devices [63].

\section{Methylxanthine therapy}

Methylxanthine compounds such as caffeine, theophylline, and aminophylline have been administered to premature infants as respiratory stimulants to decrease AOP [50]. These drugs are powerful central nervous system stimulants and likely reduce apnea by multiple physiological and pharmacological mechanisms. They are non-selective antagonists of adenosine receptors that increase minute ventilation, $\mathrm{CO}_{2}$ sensitivity, and neural respiratory drive while decreasing the hypoxic depression of breathing. Methylxanthines also improve diaphragmatic contraction and respiratory muscle function $[4,34,57]$.

Systematic reviews of caffeine therapy in AOP have shown that both caffeine and theophylline are effective in reducing apnea within 2 to 7 days of starting treatment. Caffeine is safer and has a wider therapeutic range than theophylline [12], and the plasma half-life of caffeine is $100 \mathrm{~h}$ compared to $30 \mathrm{~h}$ for theophylline [57]. A recent multicenter clinical trial has resolved the longstanding uncertainty about the long-term safety and efficacy of methylxanthine therapy as treatment for AOP. It revealed that caffeine reduced the rate of bronchopulmonary dysplasia and neurodevelopmental disabilities [75, 76]. Although the potential mechanisms of neuroprotective effect are not completely known, the decrease of ventilator-induced lung injury due to the use of caffeine may partly explain the neuroprotective outcome.

At what dose should caffeine be given? Because caffeine is usually available as caffeine citrate, the active component comprises only $50 \%$ of the total dose. In a study of caffeine for AOP, a loading dose of $10 \mathrm{mgkg}$ caffeine (i.v. or orally) and a maintenance dose of $2.5 \mathrm{mgkg}$ once daily worked efficiently [76]. A randomized controlled trial [82] compared three loading doses of 30,15 , or $3 \mathrm{mg} / \mathrm{kg}$ of caffeine followed by half of the loading doses every $24 \mathrm{~h}$. The two higher dose groups had less apnea than the lowest dose group. In another randomized controlled trial, Steer et al. [81] compared a very high loading dose of $40 \mathrm{mg} / \mathrm{kg}$ caffeine (followed by 20 $\mathrm{mg} / \mathrm{kg}$ every $24 \mathrm{~h}$ ) with a standard loading dose of $10 \mathrm{mg} / \mathrm{kg}$ (followed by $5 \mathrm{mg} / \mathrm{kg}$ every $24 \mathrm{~h}$ ). The high-dose group showed significant reductions in extubation failure, duration of ventilation, and apnea after extubation compared with the low-dose group. Thus, a higher dose of caffeine appears to 
be more effective in preventing AOP. However, very high dose of caffeine was reported to have adverse effects. Hoecker et al. [35] found that a high loading dose of $25 \mathrm{mg} / \mathrm{kg}$ of caffeine reduced blood flow velocity in the cerebral arteries of premature infants by about $20 \%$, whereas a loading dose of $10 \mathrm{mg} / \mathrm{kg}$ caffeine resulted in reduction of cerebral blood flow velocity that recovered $4 \mathrm{~h}$ post-dose [92]. Therefore, caffeine at a loading dose of $10 \mathrm{mgkg}$ followed by $5 \mathrm{mgkg}$ /day maintenance may be an adequate starting point. Only when refractory AOP persists should a switch to a higher dose be considered [81]. For theophylline use, the recommended loading dose is $5-6 \mathrm{mg} / \mathrm{kg}$, followed by maintenance doses of $2-6 \mathrm{mg} / \mathrm{kg} /$ day divided into two or three daily doses [92].

Methylxanthines do carry some risks of adverse events. Toxic levels may produce tachycardia, cardiac dysrhythmias, and feeding intolerance or, at very high doses, may precipitate seizures. Mild diuresis and delayed gastric emptying can also be seen in very low birth weight infants. Methylxanthines also increase energy expenditure, possibly leading to diminished growth in premature infants, suggesting an extra caloric requirement is necessary in infants treated with theophylline $[2,19,79]$.

\section{Other interventions with unclear efficacy}

\section{Kangaroo mother care}

Maternal kangaroo care, also known as skin-to-skin care for premature infants, has achieved widespread acceptance for stable infants because of the calming effects on the baby's clinical status and vital signs [30]. However, the effect of this approach for the treatment of AOP remains controversial. A randomized controlled trial showed that infants receiving kangaroo care had fewer apneic and bradycardic events than those who did not receive kangaroo care [46]. In a different study, researchers found that apneic and bradycardic events were increased during kangaroo care [16]. Recently, Heimann et al. [33] found that the effect of kangaroo care on improvement of apnea was the same as that seen with prone positioning. The use of kangaroo care for treatment of AOP still requires further study.

\section{Sensory stimulations}

Several studies suggest that sensory stimulants, including tactile and olfactory stimulation, are useful in the treatment or prevention of AOP. Tactile stimulation is the most common intervention in response to AOP. This simple intervention most likely works by generating excitatory, nonspecific neuronal activity in the brainstem center to stimulate respiratory activity [32]. An older randomized controlled trial showed that tactile stimulation reduced the frequency of apnea by 35\% [40]. However, cutaneous stimulation often arouses the infant and markedly affects breathing pattern in premature infants. Bloch-Salisbury et al. [13] have demonstrated that subthreshold stimulation for causing arousal from sleep to wakefulness could decrease apnea by approximately $65 \%$. However, systematic review has shown that kinesthetic stimulation is not effective at preventing AOP [62].

Olfactory stimulation has also been used for the treatment of AOP. Pleasant odors elicited increased respiratory drive, whereas unpleasant odors caused decreased respiratory effort, during active sleep when apnea is more common [5]. Vanillin, a stimulus known to affect the olfactory nerve, was used to treat refractory apnea and bradycardia unresponsive to both caffeine and doxapram [49]. They found that patients exposed to 15 drops of vanillin had significantly fewer apneic episodes [49]. Therefore, researchers concluded that the presence of a pleasant odor helped the infants to better regulate their respiratory patterns. Since this experiment was performed for only $24 \mathrm{~h}$, it is not known how long this beneficial effect persists.

\section{$\mathrm{CO}_{2}$ inhalation}

$\mathrm{CO}_{2}$ is the physiologic stimulus for breathing in mammals. Apnea occurs when the $\mathrm{CO}_{2}$ baseline decreases below the apnea threshold. A rise in $\mathrm{CO}_{2}$ of 1 to $2 \mathrm{mmHg}$ above the apnea threshold will reduce or abolish apnea [38, 42]. Recently, a randomized controlled trial of theophylline versus $\mathrm{CO}_{2}$ inhalation for treating $\mathrm{AOP}$ showed that inhalation of a low $\mathrm{CO}_{2}$ concentration $(0.8 \%)$ in premature infants is as effective as theophylline in decreasing apnea. This exposure to $0.8 \% \mathrm{CO}_{2}$ also had no effect on cerebral blood flow velocity [3]. The authors concluded that $\mathrm{CO}_{2}$ may be a better treatment for AOP than methylxanthines. However, it is likely that infants will quickly accommodate to an inspiratory $\mathrm{CO}_{2}$ concentration, and the effectiveness of long-term exposure is not known.

\section{Orogastric feeding tube placement}

An increase in upper airway resistance may also play a significant role in AOP. Nasogastric tubes have been documented to increase nasal airway resistance by $50 \%$ [15]. Therefore, orogastric feeding tubes are sometimes preferred in premature infants with apneic events. However, a recent randomized controlled trial showed that the placement of the feeding tube had no significant effect on bradycardia and desaturation [15]. There does not appear to be a benefit of using an oral instead of a nasogastric tube for feeding infants with AOP. Interestingly, transpyloric feedings, especially when limited to human milk, have recently been shown to be safe and reduce episodes of 
apnea and bradycardia in premature infants with suspected gastroesophageal reflux in a retrospective single-center cohort study [47].

\section{Thermoneutral range}

A mild increase in body temperature in infants enhances the instability of the breathing pattern [72]. In a recent study, less apnea was found at an incubator temperature of $30.4^{\circ} \mathrm{C}$ than at $32.5^{\circ} \mathrm{C}$ [91]. Of course, a number of factors play a role in incubator and baby temperature, but overheating may be a factor in AOP. However, a specific environmental temperature to reduce the incidence or severity of AOP is not known, and more research is required.

\section{Red blood cell transfusions}

Anemia can lead to AOP, and a proposed mechanism to treat AOP is transfusion of red blood cells to increase oxygen carrying capacity. However, data on the effect of blood transfusion on AOP is not clear. Studies focusing on bradycardia caused by apnea showed no effect of transfusion in either mildly or severely anemic infants [96]. Recently, a randomized trial [8] comparing a liberal with restrictive transfusion pattern in premature infants found that infants had more frequent apnea in the restrictive transfusion group. Furthermore, a retrospective study on the risks and benefits of transfusions in extremely low birth weight infants found that transfusions were not associated with apnea frequency but were associated with increased risk of bronchopulmonary dysplasia and necrotizing enterocolitis [93]. Based on these conflicting data, we think that the evidence is insufficient to recommend transfusion to treat AOP in anemic infants.

\section{Doxapram}

Doxapram is a potent respiratory stimulant used for the management of apnea refractory to methylxanthine therapy [14]. The use of doxapram is controversial because of its reported adverse effects [14, 97]. The short-term side effects of Doxapram include irritability, elevated blood pressure, and gastric retention, which are usually seen clinically with doses above $1.5 \mathrm{mg} / \mathrm{kg} / \mathrm{h}$ [9]. The long-term side effects of doxapram remain unknown. Dani et al. [23] evaluated the effects of doxapram on cerebral hemodynamics in premature infants, using cerebral Doppler ultrasonography and near-infrared spectroscopy. They found doxapram induced an increase in cerebral oxygen consumption and a decrease in oxygen delivery. This is probably mediated by a decrease of cerebral blood flow. Therefore, doxapram is not routinely recommended for AOP since its side effects and long-term benefits versus potential harm are concerning.

\section{Consequences of $\mathrm{AOP}$}

\section{Short-term consequences}

In premature infants, desaturation and bradycardic episodes often occur along with apnea. Bradycardia usually begins after the onset of hypoxemia and can initially be accompanied by a rise in stroke volume [68]. However, prolonged apnea and bradycardia can decrease the systemic blood pressure and lead to cerebral hypoperfusion, which may contribute to hypoxic-ischemic injury of the immature brain [66].

\section{Long-term consequences}

The long-term consequences of apnea are controversial [64]. It is difficult to prove a link between apnea and poor neurodevelopmental outcomes due to the possible coexistence of neurological injury in premature infants.

In early studies, no differences in neurodevelopmental outcomes were found between AOP and control infants. Delayed mental and motor development was seen in both premature infant groups [43]. However, Janvier et al. [37] found that an increased number of AOP days were associated with neurodevelopmental impairment such as cerebral palsy and blindness at 3 years of age. Recently, researchers found that a higher frequency and severity of AOP were associated with a higher incidence of unfavorable outcomes or death [67]. One explanation for these findings is that multiple recurrent hypoxic and bradycardia following AOP may cause long-term cerebral dysfunction. However, these two studies did not establish whether apnea was a cause or a result of underlying cerebral dysfunction.

Whether persistent AOP may lead to sudden infant death syndrome was only recently clarified. The risk of sudden infant death syndrome in premature infants is three times higher than that of full-term infants [36]. However, the risk factors for sudden infant death syndrome in premature infants are strongly associated with maternal age, tobacco use, meteorological factors, and genetics but not AOP [22, $28,48,90]$.

Generally speaking, the lower the gestational age, the longer the period that AOP persists. AOP disappears in most infants by 36 to 40 weeks postconceptional age. However, extremely premature infants (24-28 gestational weeks) are at risk for experiencing apnea beyond 38 to 40 weeks postconceptional age [29].

\section{Summary}

Apnea is a very common symptom in premature infants. In the majority of infants, apnea is a time-limited problem, disappearing by term postconceptional age. The long-term 
consequences of severe, recurrent apnea-associated bradycardia and desaturation are not known. Many interventions for apnea, including some pharmacologic therapies, physical or mechanical methods, remain unproven for long-term efficacy. Further investigation of the pathogenesis and consequences of apnea in premature infants will help us understand the long-term risks. In addition, more research is necessary to clarify optimal treatment regimens.

Acknowledgments This work was supported by grants from the National Natural Science Foundation of China (No.30825039, No.30973236, and No.30770748), the Ministry of Education of China (IRT0935; 20070610092), and the Health Department and Human Resource Department of Sichuan Province (080236, 078RC-256515).

Conflict of interest statement There are no conflicts of interest to disclose.

Open Access This article is distributed under the terms of the Creative Commons Attribution Noncommercial License which permits any noncommercial use, distribution, and reproduction in any medium, provided the original author(s) and source are credited.

\section{References}

1. Abu-Shaweesh JM (2007) Activation of central adenosine $A_{2 A}$ receptors enhances superior laryngeal nerve stimulation-induced apnea in piglets via a GABAergic pathway. J Appl Physiol 103 (4): 1205-1211

2. Adén U (2011) Methylxanthines during pregnancy and early postnatal life. Handb Exp Pharmacol 200:373-389

3. Al-Saif S, Alvaro R, Manfreda J et al (2008) A randomized controlled trial of theophylline versus $\mathrm{CO} 2$ inhalation for treating apnea of prematurity. J Pediatr 153(4):513-518

4. Aranda JV, Beharry K, Valencia GB et al (2010) Caffeine impact on neonatal morbidities. J Matern Fetal Neonatal Med 23(Suppl 3):20-23

5. Arzi A, Sela L, Green A et al (2010) The influence of odorants on respiratory patterns in sleep. Chem Senses 35(1):31-40

6. Baird TM (2004) Clinical correlates, natural history and outcome of neonatal apnoea. Semin Neonatol 9(3):205-211

7. Bauschatz AS, Kaufmann CM, Haensse D et al (2008) A preliminary report of nursing in the three-stair-position to prevent apnoea of prematurity. Acta Paediatr 97(12):1743-1745

8. Bell EF, Strauss RG, Widness JA et al (2005) Randomized trial of liberal versus restrictive guidelines for red blood cell transfusion in preterm infants. Pediatrics 115(6):1685-1691

9. Bénard M, Boutroy MJ, Glorieux I, Casper C (2005) Determinants of doxapram utilization: a survey of practice in the French Neonatal and Intensive Care Units. Arch Pediatr 12(2):151-155

10. Bhat RY, Hannam S, Pressler R et al (2006) Effect of prone and supine position on sleep, apneas, and arousal in preterm infants. Pediatrics 118(1):101-107

11. Bishara N, Ohls RK (2009) Current controversies in the management of the anemia of prematurity. Semin Perinatol 33 (1):29-34

12. Bloch-Salisbury E, Hall MH, Sharma P et al (2010) Heritability of apnea of prematurity: a retrospective twin study. Pediatrics 126 (4):779-787

13. Bloch-Salisbury E, Indic P, Bednarek F, Paydarfar D (2009) Stabilizing immature breathing patterns of preterm infants using stochastic mechanosensory stimulation. J Appl Physiol 107 (4):1017-1027

14. Bober K, Swietliński J, Musialik-Swietlińska E et al (2008) Recommended treatment of apnea in premature infants. A review based on literature and own experience. Med Wieku Rozwoj 12(4 Pt 1):846-850

15. Bohnhorst B, Cech K, Peter C, Doerdelmann M (2010) Oral versus nasal route for placing feeding tubes: no effect on hypoxemia and bradycardia in infants with apnea of prematurity. Neonatology 98(2):143-149

16. Bohnhorst B, Gill D, Dordelmann M et al (2004) Bradycardia and desaturation during skin-to-skin care: no relationship to hyperthermia. J Pediatr 145(4):499-502

17. Cardot V, Chardon K, Tourneux P et al (2007) Ventilatory response to a hyperoxic test is related to the frequency of short apneic episodes in late preterm neonates. Pediatr Res 62(5):591596

18. Carlo WA, Martin RJ, Difiore JM (1988) Differences in $\mathrm{CO}_{2}$ threshold of respiratory muscles in preterm infants. J Appl Physiol 65(6):2434-2439

19. Carnielli VP, Verlato G, Benini F et al (2000) Metabolic and respiratory effects of theophylline in the preterm infant. Arch Dis Child Fetal Neonatal Ed 83(1):F39-F43

20. Condino AA, Sondheimer J, Pan Z et al (2006) Evaluation of infantile acid and nonacid gastroesophageal reflux using combined $\mathrm{pH}$ monitoring and impedance measurement. J Pediatr Gastroenterol Nutr 42(1):16-21

21. Corvaglia L, Mariani E, Aceti A et al (2009) Combined oesophageal impedance-pH monitoring in preterm newborn: comparison of two options for layout analysis. Neurogastroenterol Motil 21(10):1027-e81

22. Courts C, Madea B (2010) Genetics of the sudden infant death syndrome. Forensic Sci Int Jul 29 [Epub ahead of print]

23. Dani C, Bertini G, Pezzati M et al (2006) Brain hemodynamic effects of doxapram in preterm infants. Biol Neonate 89(2):6974

24. Darnall RA (2010) The role of $\mathrm{CO}_{2}$ and central chemoreception in the control of breathing in the fetus and the neonate. Respir Physiol Neurobiol 173(3):201-212

25. Darnall RA, Ariagno RL, Kinney HC (2006) The late preterm infant and the control of breathing, sleep, and brainstem development: a review. Clin Perinatol 33(4):883-914

26. De Paoli AG, Davis PG, Faber B, Morley CJ (2008) Devices and pressure sources for administration of nasal continuous positive airway pressure (NCPAP) in preterm neonates. Cochrane Database Syst Rev 23(1):CD002977b

27. Di Fiore JM, Arko M, Churbock K et al (2009) Technical limitations in detection of gastroesophageal reflux in neonates. $\mathrm{J}$ Pediatr Gastroenterol Nutr 49(2):177-182

28. Dietz PM, England LJ, Shapiro-Mendoza CK et al (2010) Infant morbidity and mortality attributable to prenatal smoking in the U. S. Am J Prev Med 39(1):45-52

29. Ducrocq S, Biran-Mucignat V, Boelle PY et al (2006) Apnea of prematurity: risk factors and ambulatory treatment with caffeine citrate. Arch Pediatr 13(10):1299-1304

30. Gathwala G, Singh B, Singh J (2010) Effect of Kangaroo Mother Care on physical growth, breastfeeding and its acceptability. Trop Doct 40(4):199-202

31. Gauda EB, McLemore GL, Tolosa J et al (2004) Maturation of peripheral arterial chemoreceptors in relation to neonatal apnoea. Semin Neonatol 9(3):181-194

32. Gaugler C, Marlier L, Messer J (2007) Sensory stimulations for the treatment of idiopathic apneas of prematurity. Arch Pediatr 14 (5):485-489

33. Heimann K, Vaessen P, Peschgens T et al (2010) Impact of skin to skin care, prone and supine positioning on cardiorespiratory 
parameters and thermoregulation in premature infants. Neonatology 97(4):311-317

34. Henderson-Smart DJ, Steer PA (2010) Caffeine versus theophylline for apnea in preterm infants. Cochrane Database Syst Rev 20 (1):CD000273

35. Hoecker C, Nelle M, Poeschl J et al (2002) Caffeine impairs cerebral and intestinal blood flow velocity in preterm infants. Pediatrics 109(5):784-787

36. Hoppenbrouwers T, Hodgman JE, Ramanathan A, Dorey F (2008) Extreme and conventional cardiorespiratory events and epidemiologic risk factors for SIDS. J Pediatr 152(5):636-641

37. Janvier A, Khairy M, Kokkotis A et al (2004) Apnea is associated with neurodevelopmenta impairment in very low birth weight infants. J Perinatol 24(12):763-768

38. Joseph LJ, Goldberg S, Picard E (2009) CO2 treatment for apnea. J Pediatr 154(4):627-628

39. Kamaluddeen M, Lodha A, Akierman A (2009) Non-Rotavirus infection causing apnea in a neonate. Indian $\mathrm{J}$ Pediatr 76 (10):1051-1052

40. Kattwinkel J, Nearman HS, Fanaroff AA et al (1975) Apnea of prematurity. Comparative therapeutic effects of cutaneous stimulation and nasal continuous positive airway pressure. J Pediatr 86 (4):588-592

41. Kelly BN, Huckabee ML, Jones RD, Frampton CM (2006) Nutritive and non-nutritive swallowing apnea duration in term infants: implications for neural control mechanisms. Respir Physiol Neurobiol 154(3):372-378

42. Khan A, Qurashi M, Kwiatkowski K et al (2005) Measurement of the $\mathrm{CO}_{2}$ apneic threshold in newborn infants: possible relevance for periodic breathing and apnea. J Appl Physiol 98(4):1171-1176

43. Koons AH, Mojica N, Jadeja N et al (1993) Neurodevelopmental outcome of infants with apnea of infancy. Am J Perinatol 10 (3):208-211

44. Lehtonen L, Martin RJ (2004) Ontogeny of sleep and awake states in relation to breathing in preterm infants. Semin Neonatol 9 (3):229-238

45. Lemyre B, Davis PG, De Paoli AG (2002) Nasal intermittent positive pressure ventilation (NIPPV) versus nasal continuous positive airway pressure (NCPAP) for apnea of prematurity. Cochrane Database Syst Rev 1:CD002272

46. Ludington-Hoe SM, Anderson GC, Swinth JY et al (2004) Randomized controlled trial of kangaroo care: cardiorespiratory and thermal effects on healthy preterm infants. Neonatal Netw 23(3):39-48

47. Malcolm WF, Smith PB, Mears S et al (2009) Transpyloric tube feeding in very low birthweight infants with suspected gastroesophageal reflux: impact on apnea and bradycardia. J Perinatol 29(5):372-375

48. Malloy MH, Freeman DH (2000) Birth weight- and gestational age-specific sudden infant death syndrome mortality: United States, 1991 versus 1995. Pediatrics 105(6):1227-1231

49. Marlier L, Gaugler C, Messer J (2005) Olfactory stimulation prevents apnea in premature newborns. Pediatrics 115(1):83-88

50. Martin RJ, Abu Shaweesh JM, Baird TM (2004) Apnoea of prematurity. Paediatr Respir Rev 5(Suppl 1):S377-S382

51. Mercer JS, Erickson-Owens DA, Graves B, Haley MM (2007) Evidence-based practices for the fetal to newborn transition. J Midwifery Womens Health 52(3):262-272

52. Mesner O, Miller MJ, Iben SC et al (2008) Hyperbilirubinemia diminishes respiratory drive in a rat pup model. Pediatr Res 64 (3):270-274

53. Millar D, Kirpalani H (2004) Benefits of non invasive ventilation. Indian Pediatr 41(10):1008-1017

54. Moretti C, Giannini L, Fassi C et al (2008) Nasal flowsynchronized intermittent positive pressure ventilation to facilitate weaning in very low-birthweight infants: unmasked randomized controlled trial. Pediatr Int 50(1):85-91
55. Moriette G, Lescure S, El Ayoubi M, Lopez E (2010) Apnea of prematurity: what's new? Arch Pediatr 17(2):186-190

56. Mousa H, Woodley FW, Metheney M, Hayes J (2005) Testing the association between gastroesophageal reflux and apnea in infants. J Pediatr Gastroenterol Nutr 41(2):169-177

57. Mueni E, Opiyo N, English M (2009) Caffeine for the management of apnea in preterm infants. Int Health 1(2):190 195

58. Naik-Mathuria B, Chang S, Fitch ME et al (2008) Patent ductus arteriosus ligation in neonates: preoperative predictors of poor postoperative outcomes. J Pediatr Surg 43(6):1100-1105

59. Nock ML, Difiore JM, Arko K, Martin RJ (2004) Relationship of the ventilatory response to hypoxia with neonatal apnea in preterm infants. J Pediatr 144(3):291-295

60. Oliveira TG, Rego MA, Pereira NC et al (2009) Prone position and reduced thoracoabdominal asynchrony in preterm newborns. J Pediatr 85(5):443-448

61. Omari TI (2009) Apnea-associated reduction in lower esophageal sphincter tone in premature infants. J Pediatr 154(3):374 378

62. Osborn DA, Henderson-Smart DJ (2002) Kinesthetic stimulation for preventing apnea in preterm infants. Cochrane Database Syst Rev 2:CD000373

63. Pantalitschka T, Sievers J, Urschitz MS et al (2009) Randomized crossover trial of four nasal respiratory support systems on apnoea of prematurity in very low birth weight infants. Arch Dis Child Fetal Neonatal Ed 94(4):245-248

64. Perlman JM (2001) Neurobehavioral deficits in premature graduates of intensive care-potential medical and neonatal environmental risk factors. Pediatrics 108(6):1339-1348

65. Peter CS, Sprodowski N, Bohnhorst B et al (2002) Gastroesophageal reflux and apnea of prematurity: No temporal relationship. Pediatrics 109(1):8-11

66. Pilcher G, Urlesberger B, Muller W (2003) Impact of bradycardia on cerebral oxygenation and cerebral blood volume during apnoea in preterm infants. Physiol Meas 24(3):671-680

67. Pillekamp F, Hermann C, Keller T et al (2007) Factors influencing apnea and bradycardia of prematurity-mplications for neurodevelopment. Neonatology 91(3):155-161

68. Poets CF (2010) Apnea of prematurity: what can observational studies tell us about pathophysiology? Sleep Med 11(7):701-707

69. Poets CF, Bodman A (2008) Sleeping position for preterm infants. Z Geburtshilfe Neonatol 212(1):27-29

70. Praud JP (2010) Upper airway reflexes in response to gastric reflux. Paediatr Respir Rev 11(4):208-212

71. Reher C, Kuny KD, Pantalitschka T et al (2008) Randomised crossover trial of different postural interventions on bradycardia and intermittent hypoxia in preterm infants. Arch Dis Child Fetal Neonatal Ed 93(4):289-291

72. Rieger-Fackeldey E, Schaller-Bals S, Schulze A (2003) Effect of body temperature on the pattern of spontaneous breathing in extremely low birth weight infants supported by proportional assist ventilation. Pediatr Res 54(3):332-336

73. Robertson CM, Watt MJ, Dinu IA (2009) Outcomes for the extremely premature infant: what is new? And where are we going? Pediatr Neurol 40(3):189-196

74. Sale SM (2010) Neonatal apnoea. Best Pract Res Clin Anaesthesiol 24(3):323-336

75. Schmidt B, Roberts RS, Davis P et al (2006) Caffeine therapy for apnea of prematurity. N Engl J Med 354(20):2112-2121

76. Schmidt B, Roberts RS, Davis P et al (2007) Long-term effects of caffeine therapy for apnea of prematurity. N Engl J Med 357 (19):1893-1902

77. Sher TR (2002) Effect of nursing in the head elevated tilt position (15 degrees) on the incidence of bradycardic and hypoxemic episodes in preterm infants. Pediatr Phys Ther 14(2):112-113 
78. Simakajornboon N, Kuptanon T (2005) Maturational changes in neuromodulation of central pathways underlying hypoxic ventilatory response. Respir Physiol Neurobiol 149(1-3):273-286

79. Skopnik H, Koch G, Heimann G (1990) Effect of methylxanthines on periodic respiration and acid gastroesophageal reflux in newborn infants. Monatsschr Kinderheilkd 138(3):123-127

80. Slocum C, Hibbs AM, Martin RJ, Orenstein SR (2007) Infant apnea and gastroesophageal reflux: a critical review and framework for further investigation. Curr Gastroenterol Rep 9(3):219224

81. Steer P, Flenady V, Shearman A et al (2004) High dose caffeine citrate for extubation of preterm infants: a randomized controlled trial. Arch Dis Child Fetal Neonatal Ed 89(6):499-503

82. Steer PA, Flenady VJ, Shearman A et al (2003) Periextubation caffeine in preterm neonates: a randomized dose response trial. J Paediatr Child Health 39(7):511-515

83. St-Hilaire M, Samson N, Duvareille C, Praud JP (2008) Laryngeal stimulation by an acid solution in the pre-term lamb. Adv Exp Med Biol 605:154-158

84. Stock C, Teyssier G, Pichot V et al (2010) Autonomic dysfunction with early respiratory syncytial virus-related infection. Auton Neurosci 156(1-2):90-95

85. Stokowski LA (2005) A primer on Apnea of prematurity. Adv Neonatal Care 5(3):155-170

86. Tamim H, Khogali M, Beydoun $\mathrm{H}$ et al (2003) Consanguinity and apnea of prematurity. Am J Epidemiol 158(10):942-946

87. Thach BT (2007) Maturation of cough and other reflexes that protect the fetal and neonatal airway. Pulm Pharmacol Ther 20 (4):365-370

88. Thompson AM, Bizzarro MJ (2008) Necrotizing enterocolitis in newborns: pathogenesis, prevention and management. Drugs 68 (9):1227-1238
89. Tipnis NA, Tipnis SM (2009) Controversies in the Treatment of Gastroesophageal Reflux Disease in Preterm Infants. Clin Perinatol 36(1):153-164

90. Töro K, Bartholy J, Pongrácz R et al (2010) Evaluation of meteorological factors on sudden cardiovascular death. J Forensic Leg Med 17(5):236-242

91. Tourneux P, Cardot V, Museux N et al (2008) Influence of thermal drive on central sleep apnea in the preterm neonate. Sleep 31 (4):549-556

92. Tracy MB, Klimek J, Hinder M et al (2010) Does caffeine impair cerebral oxygenation and blood flow velocity in preterm infants? Acta Paediatr 99(9):1319-1323

93. Valieva OA, Strandjord TP, Mayock DE, Juul SE (2009) Effects of transfusions in extremely low birth weight infants: a retrospective study. J Pediatr 155(3):331-337

94. Vento M, Asensi M, Sastre J et al (2003) Oxidative stress in asphyxiated term infants resuscitated with $100 \%$ oxygen. J Pediatr 142(3):240-246

95. Vialet R, Nau A (2009) Effect of head posture on pediatric oropharyngeal structures: implications for airway management in infants and children. Curr Opin Anaesthesiol 22(3):396-399

96. Westkamp E, Soditt V, Adrian S et al (2002) Blood transfusion in anemic infants with apnea of prematurity. Biol Neonate 82 (4):228-232

97. Yost CS (2006) A new look at the respiratory stimulant doxapram. CNS Drug Rev 12(3-4):236-249

98. Zaidi SI, Jafri A, Martin RJ, Haxhiu MA (2006) Adenosine A2A receptors are expressed by GABAergic neurons of medulla oblongata in developing rat. Brain Res 1071(1):42-53

99. Zhang L, Wilson CG, Liu S et al (2003) Hypercapnia-induced activation of brainstem GABAergic neurons during early development. Respir Physiol Neurobiol 136(1):25-37 